\title{
Influence of Fe Addition on the Martensitic Transformation, Structure and Magnetic Properties of Metamagnetic Ni-Co-Mn-Sn Alloys
}

\author{
A. Wójcik ${ }^{a, *}$, W. Maziarz ${ }^{a}$, M.J. Szczerba $^{a}$, M. Sikora ${ }^{b}$, Ł. Hawelek ${ }^{c}$ And P. Czaja ${ }^{a}$ \\ ${ }^{a}$ Institute of Metallurgy and Materials Science, Polish Academy of Sciences, \\ W.S. Reymonta 25, 30-059 Krakow, Polska \\ ${ }^{b}$ Academic Centre for Materials and Nanotechnology, AGH University of Science and Technology, \\ al. A. Mickiewicza 30, 30-059 Krakow, Polska \\ ${ }^{c}$ Institute of Non-Ferrous Metals, J. Sowińskiego 5, 44-100 Gliwice, Polska
}

\begin{abstract}
In this study the effect of $\mathrm{Fe}$ for $\mathrm{Ni}$ substitution in $\mathrm{Ni}_{44} \mathrm{Co}_{6} \mathrm{Mn}_{39} \mathrm{Sn}_{11}$ metamagnetic shape memory alloys on their structure, magneto-structural transformation characteristics, magnetic and magnetocaloric properties was studied. The results show that the structure and martensite transformation behavior strongly depends on the Fe concentration. The martensitic transformation temperature decreases with 1 at.\% of $\mathrm{Fe}$ and is suppressed with higher Fe content. It was further found that substitution of $\mathrm{Fe}$ for $\mathrm{Ni}$ leads to lowering of the value of magnetic entropy change.
\end{abstract}

DOI: 10.12693/APhysPolA.130.1026

PACS/topics: 75.30.Sg, 81.30.Kf

\section{Introduction}

$\mathrm{Ni}-\mathrm{Co}-\mathrm{Mn}-\mathrm{Sn}$ Heusler alloys have attracted much attention because of their potential applications as multifunctional materials [1-3]. This is related to the ability of these alloys to undergo martensitic transformation $\left(M_{\mathrm{T}}\right)$ from high symmetry, ferromagnetic austenite phase to lower symmetry, weakly magnetic martensite phase $[4,5]$. Due to the magnetization difference between martensite and austenite an applied magnetic field can induce in these systems a reverse martensitic transformation (RMT), a phenomenon known as metamagnetic shape memory effect (MSME). An abrupt magnetization change across the transition is the source of an inverse magnetocaloric effect (IMCE), which is perspective for environmentally magnetic refrigeration $[6,7]$. It has been found that introduction of $\mathrm{Co}$ for $\mathrm{Ni}$ decreases the $M_{\mathrm{T}}$ temperature while increasing the Curie temperature [8-10]. The $\mathrm{Ni}_{44} \mathrm{Co}_{6} \mathrm{Mn}_{39} \mathrm{Sn}_{11}$ alloys show $M_{\mathrm{T}}$ at $342 \mathrm{~K}$ and the $T_{\mathrm{C}}$ at $396 \mathrm{~K} \mathrm{[5],} \mathrm{which} \mathrm{is} \mathrm{in-}$ convenient for practical applications, for which the $M_{\mathrm{T}}$ should be set near room temperature. This can be achieved for instance by composition modification e.g. by addition of a fifth element into the quaternary system. Such replacement of $\mathrm{Ni}$ or $\mathrm{Mn}$ by $\mathrm{Fe}$ has been reported to impact the characteristic $M_{\mathrm{T}}$ and $T_{\mathrm{C}}$ temperatures [9, 11-14]. Previously the effect of Ti [15], $\mathrm{Nb}$ [16], In [17] substitution for $\mathrm{Ni}$ and $\mathrm{Sn}$ have been studied in $\mathrm{Ni}_{43-x} \mathrm{Ti}_{x} \mathrm{Co}_{7} \mathrm{Mn}_{43} \mathrm{Sn}_{7}, \mathrm{Ni}_{45-x} \mathrm{Nb}_{x} \mathrm{Co}_{5} \mathrm{Mn}_{40} \mathrm{Sn}_{10}$, $\mathrm{Ni}_{45} \mathrm{Co}_{5} \mathrm{Mn}_{40} \mathrm{In}_{x} \mathrm{Sn}_{10-x}$ and showed $M_{\mathrm{T}}$ decreasing with addition of $\mathrm{Ti}$ and $\mathrm{Nb}$ and increasing with In.

\footnotetext{
*corresponding author; e-mail: a.wojcik@imim.pl
}

In the present study the effect of Fe substitution for $\mathrm{Ni}$ on structural and magnetic properties in $\mathrm{Ni}-\mathrm{Co}-\mathrm{Mn}-\mathrm{Sn}$ alloys is reported and discussed.

\section{Experimental}

$\mathrm{Ni}_{44-x} \mathrm{Fe}_{x} \mathrm{Co}_{6} \mathrm{Mn}_{39} \mathrm{Sn}_{11}(x=0,1,2,4$ at.\%) alloys were prepared by induction melting technique from pure elements (99.9\%) of Ni, Fe, Co, Mn, Sn in argon atmosphere. The samples are referred to $\mathrm{Fe} 0, \mathrm{Fe} 1, \mathrm{Fe} 2$, and $\mathrm{Fe} 4$, respectively. The ingots were annealed in vacuum at $1223 \mathrm{~K}$ for $5 \mathrm{~h}$ in order to obtain good homogeneity of the solidified alloys. Then they were heat treated at $1173 \mathrm{~K}$ for $1.5 \mathrm{~h}$ followed by quenching in ice water. The phase identification of samples were performed by X-ray diffraction method at $293 \mathrm{~K}$ using a Rigaku MiniFlex 600 diffractometer with $\mathrm{Cu} K_{\alpha}$ radiation. Microstructure and chemical composition of samples were studied using Tecnai G2 transmission electron microscopy (TEM) operating at $200 \mathrm{kV}$, equipped with energy dispersive X-ray microanalyser (EDX). Magnetostructural transformations and magnetic properties of alloys were determined by means of LakeShore 7407 vibrating sample magnetometer (VSM) equipped with Janis made $\mathrm{LN}_{2}$ cryostat.

\section{Results}

Figure 1 shows the set of XRD patterns of $\mathrm{Fe} 0-\mathrm{Fe} 4$ alloys recorded at room temperature (RT). For Fe0 alloy, the diffraction peaks can be well indexed as a mixture of four-layered orthorhombic $4 O$ martensite with trace amount of $L 2_{1}$ austenite. Addition of 1 at.\% of $\mathrm{Fe}$ increases the volume fraction of austenite phase with simultaneous decrease of the martensite. Increase of $\mathrm{Fe}$ content up to 2 at.\% caused the formation of single phase 
$L 2_{1}$ austenite structure in $\mathrm{Fe} 2$ alloy. Further increase of Fe content also leads to formation of a two-phase structure, however other than that of Fe1 alloy. Apart from peaks of the austenite $L 2_{1}$ structure two weak reflections corresponding to $\gamma$ phase were also observed $[14,18]$. In order to better understand the effect of the substitution of Ni by Fe TEM observations were performed.

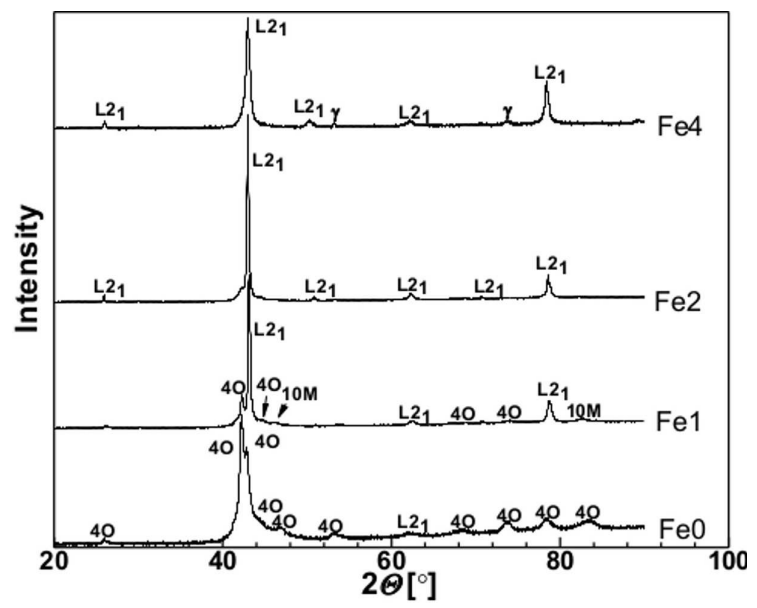

Fig. 1. XRD patterns of $\mathrm{Ni}_{44-x} \mathrm{Fe}_{x} \mathrm{Co}_{6} \mathrm{Mn}_{39} \mathrm{Sn}_{11}$ alloys recorded at RT.

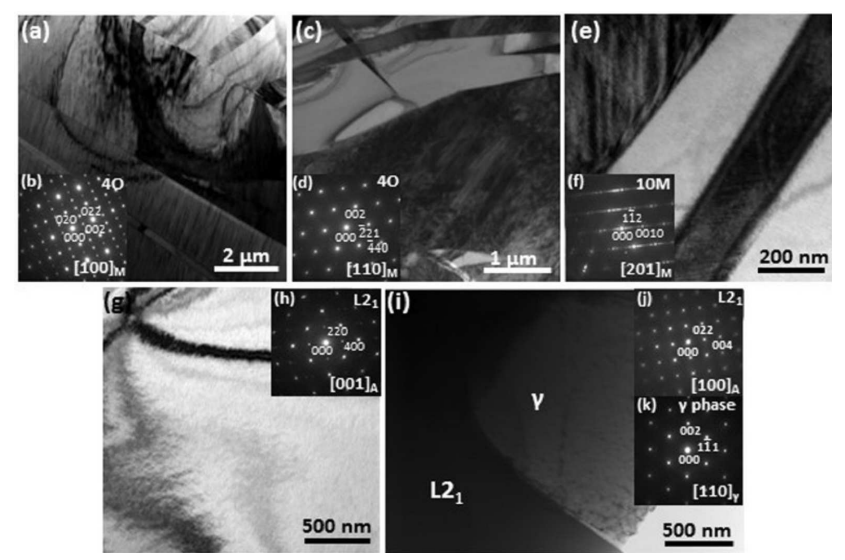

Fig. 2. TEM BF images of (a) Fe0, (c) and (e) Fe1, (g) Fe2, (i) Fe4 alloys. The insets show corresponding SADPs for $\mathrm{Fe} 0$ (b), Fe1 (d) and (f), Fe2 (h), Fe4 (j) and $(\mathrm{k})$.

Figure 2 shows bright field (BF) micrographs and selected area diffraction patterns (SADPs) taken from these regions, presented in the lower insets of BFs for all samples. The crystal structure of martensite of $\mathrm{Fe} 0$ (Fig. 2a and b) was identified as modulated four-layered orthorhombic 4O. BF micrographs and the corresponding SADPs of Fe1 sample indicate that sample consists of two types of martensite. The first one can be indexed as $4 O$ (Fig. 2c,d) and the second one corresponds to five-layered monoclinic $10 M$ martensite (Fig. 2e,f) where four satellite spots between main reflections are visible. In Fig. $2 \mathrm{~g}$ and $\mathrm{h}$ BF micrograph and corresponding SADPs are shown, which indicate that sample consists of the well-known $L 2_{1}$ austenitic structure. As was determined from X-ray diffraction experiments (Fig. 1) the Fe4 alloy is a mixture of a two-phase structure consisting of austenite and $\gamma$ phase. Figure 2i presents BF micrograph and corresponding SADPs (Fig. 2j,k) of Fe4 alloy. Based on EDS results, in the case of $\mathrm{Fe} 0, \mathrm{Fe} 1$ and $\mathrm{Fe} 2$ contents of elements are close to nominal except of small difference of Mn concentration which is connected with evaporation process. The $e / a$ ratios were calculated from the sum of $d$ and $s$ electrons for $\mathrm{Mn}(7), \mathrm{Ni}(10), \mathrm{Co}(9), \mathrm{Fe}(8), s$ and $p$ electrons for $\mathrm{Sn}(4)$. The $e / a$ values are 8.15, 8.05, 8.03 for $\mathrm{Fe} 0, \mathrm{Fe} 1$, and $\mathrm{Fe} 2$, respectively. For Fe4 sample strong chemical segregation between the matrix and precipitates of $\gamma$ phase can be observed. The chemical composition for the matrix and $\gamma$ phase is: $\mathrm{Ni}-40.9, \mathrm{Fe}-2.7$, Co - 6.3, $\mathrm{Mn}-36.1, \mathrm{Sn}-14.1$ at. $\%$ and $\mathrm{Ni}-32.4, \mathrm{Fe}$ - 11.0, Co - 14.0, Mn - 40.7, Sn - 1.9 at.\%, respectively. One can clearly see that $\gamma$ phase is enriched in Fe, Co, and Mn with small amount of dissolved Sn as compared to the matrix being in good agreement with the other results [14]. It is obvious that increase of Sn and decrease of $\mathrm{Ni}, \mathrm{Fe}$, and $\mathrm{Co}$ in the matrix causes a decrease of the $e / a$ ratio making the $M_{\mathrm{T}}$ temperature also to decrease. The magneto-structural transformations occurring during cooling and heating at low magnetic field were analyzed using the VSM technique.
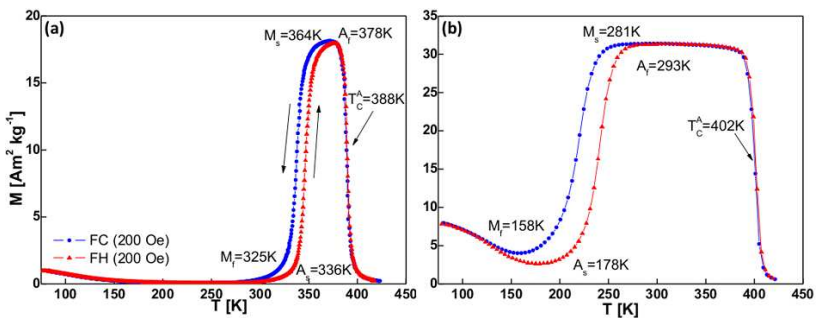

Fig. 3. Magnetization $M(T)$ curves of (a) Fe0, (b) Fe1 alloys under magnetic field of 200 Oe.

Figure 3 presents temperature dependent magnetization profiles $M(T)$ measured during cooling (FC) and heating $(\mathrm{FH})$ (marked by arrows) under external field of 200 Oe for $\mathrm{Fe} 0$ and $\mathrm{Fe} 1$ samples. Upon cooling samples undergo magnetic transition from para-austenite to ferroaustenite at $T_{\mathrm{C}} 388 \mathrm{~K}$ and $402 \mathrm{~K}$ for $\mathrm{Fe} 0$ and Fe1, respectively. With further cooling the drop of magnetization associated with the $M_{\mathrm{T}}$ is observed. During heating the reverse martensitic transition is observed. Characteristic temperatures are as follows: $M_{\mathrm{s}}=364 \mathrm{~K}, M_{\mathrm{f}}=320 \mathrm{~K}$, $A_{\mathrm{s}}=336 \mathrm{~K}, A_{\mathrm{f}}=378 \mathrm{~K}$ for $\mathrm{Fe} 0$ and $M_{\mathrm{s}}=281 \mathrm{~K}$, $M_{\mathrm{f}}=158 \mathrm{~K}, A_{\mathrm{s}}=178 \mathrm{~K}, A_{\mathrm{f}}=293 \mathrm{~K}$ for Fe1. The difference of $M_{\mathrm{s}}$ temperature between $\mathrm{Fe} 0$ and Fe1 samples can be explained based on $e / a$ ratio theory since $\mathrm{Fe} 0$ has a higher $e / a$ ratio than Fe1 [19]. In the case of alloys Fe2 and Fe4 no martensitic transformation was observed in the investigated temperature range. The main reason is the precipitation of the $\gamma$ phase which strongly changes composition of austenite and also the $e / a$ ratio leading to a decrease of the $M_{\mathrm{T}}$ temperatures or even to its total 
vanish of the $M_{\mathrm{T}}[5,19]$. Addition of Fe into Ni-Co-MnSn alloys raises the $T_{\mathrm{C}}$ temperature of austenite for Fe1. However, further addition of Fe decreases the $T_{\mathrm{c}}$ temperature. It is a consequence of strong relation between $\mathrm{Mn}$ and Fe atoms [13]. On the other hand, its decrease may be ascribed to the precipitation of $\gamma$ phase and should be taken into further investigation.
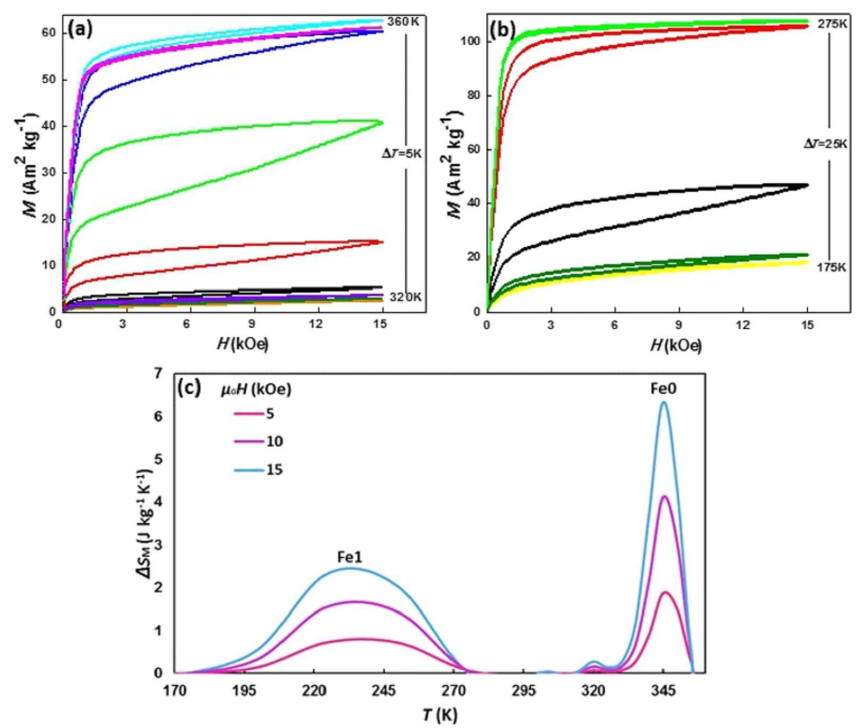

Fig. 4. $\quad M(H)$ curves for Fe0 (a) and Fe1 (b). (c) Magnetic entropy change of $\mathrm{Fe} 0$ and $\mathrm{Fe} 1$ for selected values of magnetic field (1-15 kOe).

Figure $4 \mathrm{a}$ and $\mathrm{b}$ demonstrates $M(H)$ curves for $\mathrm{Fe} 0$ and Fe1 alloys at different temperatures. Before each measurement samples were cooled below $M_{\mathrm{f}}$ temperature then heated to the temperature of measurement. Results indicate metamagnetic behavior, accompanied by transformation from martensite to austenite and is related to $\Delta M$ across $M_{\mathrm{T}}$. Based on this data magnetic entropy change $\Delta S_{M}$ was calculated using Maxwell's relation. In Fig. 4c temperature dependence of $\Delta S_{M}$ with magnetic field change $\Delta H=1-15 \mathrm{kOe}$ for $\mathrm{Fe} 0$ and $\mathrm{Fe} 1$ samples are presented. The maxima of $\Delta S_{M}$ in a magnetic field of $15 \mathrm{kOe}$ are 6.3 and $2.3 \mathrm{~J} \mathrm{~K}^{-1} \mathrm{~kg}^{-1}$ at $345 \mathrm{~K}$ and $225 \mathrm{~K}$ for $\mathrm{Fe} 0$ and $\mathrm{Fe} 1$, respectively.

\section{Conclusions}

The structure, magneto-structural behavior and magnetic entropy change of multielement $\mathrm{Ni}-\mathrm{Fe}-\mathrm{Co}-\mathrm{Mn}-\mathrm{Sn}$ bulks have been investigated. It was found that:

- With Fe addition the crystal structure changes accordingly: $4 O+L 2_{1} \stackrel{1}{\stackrel{\text { at. } \% \mathrm{Fe}}{\longrightarrow}} 4 O+10 M+L 2_{1} \stackrel{2}{2} \stackrel{\text { at. } \% \mathrm{Fe}}{\longrightarrow}$ $L 2_{1} \stackrel{4}{\stackrel{\text { at. } \% \mathrm{Fe}}{\longrightarrow}} L 2_{1}+\gamma$

- With addition of 1 at.\% of Fe, $M_{\mathrm{T}}$ temperature decreases then with further addition of Fe totally disappears in the investigated temperature range which is a consequence of precipitation of $\gamma$ phase.
- $\Delta S_{M}$ decreases from $6.3 \mathrm{~J} \mathrm{~kg}^{-1} \mathrm{~K}^{-1}(1.5 \mathrm{~T})$ for Fe0 to $2.3 \mathrm{~J} \mathrm{~kg}^{-1} \mathrm{~K}^{-1}(1.5 \mathrm{~T})$ for Fe1.

The obtained results show that optimization of magnetostructural properties is possible by obtaining multifuctional alloy which makes them a potential candidate for MSME applications.

\section{Acknowledgments}

This work was financially supported by the Polish National Centre for Research and Development in the frame of Project No. PBS/A5/36/2013.

\section{References}

[1] C. Jinga, Z. Li, H.L. Zhang, J.P. Chen, Y.F. Qiao, S.X. Cao, J.C. Zhang, Eur. Phys. J. B 67, 193 (2009).

[2] A. Gosh, K. Mandal, Eur. Phys. B 86, 378 (2013).

[3] V. Srivastava, X. Chen, R.D. James, Appl. Phys. Lett. 97, 014101 (2010).

[4] L.H. Yang, H. Zhang, F.X. Hu, J.R. Sun, L.Q. Pan, B. Shen, J. Alloys Comp. 588, 46 (2014).

[5] D.Y. Cong, S. Roth, L. Schulz, Acta Mater. 60, 5335 (2012).

[6] B. Gao, F.X. Hu, J. Shen, J. Wang, J.R. Sun, B.G. Shen, J. Magn. Magn. Mater. 321, 2571 (2009).

[7] R. Kainuma, Y. Imano, W. Ito, H. Morito, Y. Sutou, K. Oikawa, A. Fujita, K. Ishiba, S. Okamoto, O. Kitakami, T. Kanomata, Appl. Phys. Lett. 88, 192613 (2006).

[8] A. Gosh, K. Mandal, J. Alloys Comp. 579, 295 (2013).

[9] T. Krenke, E. Duman, M. Acet, X. Moya, L. Manosa, A. Planes, J. Appl. Phys. 102, 033903 (2007).

[10] X. Chen, V.B. Naik, R. Mahendiran, R.V. Ramanujan, J. Alloys Comp. 618, 187 (2015).

[11] J.L. Yan, Z.Z. Li, X. Chen, K.W. Zhou, S.X. Shen, H.B. Zhou, J. Alloys Comp. 506, 516 (2010).

[12] Y. Ma, S. Yang, Y. Liu, X. Liu, Acta Mater. 57, 3232 (2009).

[13] K. Fukushima, K. Sano, T. Kanomata, H. Nishihara, Y. Furutani, T. Shishido, W. Ito, R.Y. Umetsu, R. Kainuma, K. Oikawa, K. Ishida, Scr. Mater. 61, 813 (2009).

[14] Z. Wu, Z. Liu, H. Yang, Y. Liu, G. Wu, R.C. Woodward, Intermetallics 19, 445 (2011).

[15] F. Chen, Y-X. Tong, B. Tian, L. Li, Y.-F. Zheng, Rare Met. 33, 516 (2013).

[16] B. Emre, N.M. Bruno, S.Y. Emre, I. Karaman, Appl. Phys. Lett. 105, 231910 (2014).

[17] Z. Guo, L. Pan, M. Yasir Rafique, X. Zheng, H. Qiu, Z. Liu, J. Alloys Comp. 577, 174 (2012).

[18] Y. Ma, S. Yang, Y. Liu, X. Liu, Acta Mater. 57, 3232 (2009).

[19] H. Zheng, W. Wang, S. Xue, Q. Zhau, J. Frenzel, Z. Luo, Acta Mater. 61, 4648 (2013). 